\title{
Studies on Xanthate/Dithiocarbamate Accelerator Combination in NR/BR Blends
}

\author{
Shiny Palaty, ${ }^{1}$ Rani Joseph ${ }^{2}$ \\ ${ }^{1}$ Department of Chemistry, Bharata Mata College, Thrikkakara, Kochi-21, Kerala, India \\ ${ }^{2}$ Department of Polymer Science and Rubber Technology, Cochin University of Science and Technology, \\ Cochin 682022, Kerala, India
}

Received 14 June 2005; accepted 25 March 2006

DOI 10.1002/app.25225

Published online in Wiley InterScience (www.interscience.wiley.com).

\begin{abstract}
Zinc butyl xanthate $\left[\mathrm{Zn}(\mathrm{bxt})_{2}\right]$ was prepared in the laboratory. The effect of this xanthate with zinc diethyl dithiocarbamate (ZDC) on the vulcanization of natural rubber (NR), polybutadiene rubber (BR), and NR/BR blend has been studied at different temperatures. The amounts of $\mathrm{Zn}(\mathrm{bxt})_{2}$ and $\mathrm{ZDC}$ in the compounds were optimized by varying the amount of ZDC from 0.75 to $1.5 \mathrm{phr}$ and $\mathrm{Zn}(\mathrm{bxt})_{2}$ from 0.75 to $1.5 \mathrm{phr}$. The cure characteristics were also studied. HAF filled NR, BR, and NR/BR blend compounds were cured at different temperatures from 60 to $150^{\circ} \mathrm{C}$. The sheets were molded and properties such as ten-
\end{abstract}

sile strength, tear strength, crosslink density and elongation at break, compression set, abrasion resistance, etc. were evaluated. The results show that the mechanical properties of $80 \mathrm{NR} / 20 \mathrm{BR}$ blends are closer to that of NR vulcanizates, properties of $60 \mathrm{NR} / 40 \mathrm{BR}$ blends are closer to BR vulcanizates, while the $70 \mathrm{NR} / 30 \mathrm{BR}$ blends show an intermediate property. (1) 2006 Wiley Periodicals, Inc. J Appl Polym Sci 103: $3516-3520,2007$

Key words: natural rubber; polybutadiene rubber; NR/BR blend; low temperature curing; mechanical properties

\section{INTRODUCTION}

Synthetic rubbers are classified into general purpose rubbers and special purpose rubbers. Polybutadiene is classified as general purpose rubbers intended for the manufacture of tires and general mechanical products. However, one type of rubber may not possess all the physical properties desired in a finished product. Much attention is currently being devoted to the simplest route for combining the outstanding properties of different existing polymers, i.e., the formation of polymer blends. ${ }^{1-5}$ For example, in tread compounds, the high abrasion resistance under certain conditions conferred by the use of BR is desirable, but the poor road holding and rib tearing properties are not, hence blends of BR with NR and styrene-butadiene rubber are employed. ${ }^{6}$

Compatibility is the fundamental property, deciding the practical utility of a polymer blend. ${ }^{7-9}$ If the two elastomers in a blend are incompatible, it will exist in the form of two separate phases and the cured blend will show inferior properties. ${ }^{10}$ The properties of miscible blends will follow relationships that are functions of composition and to some extend, the degree of interaction between the blend components. ${ }^{11,12}$

The mechanical properties of nonstress crystallizing rubbers can be greatly improved by the incorpo-

Correspondence to: S. Palaty (shinypalaty@yahoo.co.uk).

Journal of Applied Polymer Science, Vol. 103, 3516-3520 (2007) C 2006 Wiley Periodicals, Inc. (3)WILEY InterScience ration of carbon black. When a filler is added to a binary elastomer blend, it goes to the less viscous polymer. When the viscosity of the less viscous polymer becomes equal to that of the highly viscous polymer, the filler will be taken up by both the polymers. ${ }^{13}$ So the low viscosity polymer gets highly loaded.

In NR/BR blends, BR shows improved tread wear and groove cracking resistance without reduction in resilience. ${ }^{14}$ Sarbach et al. reported a 20\% higher tread wear index for $50 / 50 \mathrm{NR} / \mathrm{BR}$ over straight NR. ${ }^{15,16}$ The most important advantage of adding BR to NR is the improved abrasion resistance.

Vulcanization temperature is very important in determining the quality of the rubber product. Optimum properties are obtained when curing is done at the lowest possible temperature. In the rubber industry, the rubber products are molded at very high temperatures. In addition to the high energy consumption, high temperature vulcanization also affects the quality and lifetime of the product. $\mathrm{Zn}(\mathrm{bxt})_{2} / \mathrm{ZDC}$ accelerator combination is found to vulcanize NR at lower temperatures, even at room temperature. ${ }^{17,18}$ It is found that the mechanical properties of the NR vulcanizate are improved with decrease in vulcanization temperature. The properties are reported to be maximum when the vulcanization temperature is $60^{\circ} \mathrm{C}^{19}$ Low temperature vulcanization is also applicable during the repairing of a rubber product. For example, in a tire industry, a tire having surface defects, after repair, is revulcanized at high temperature. This will 
TABLE I

Formulation of Mixes

\begin{tabular}{lcccc}
\hline \multicolumn{1}{c}{ Mix } & A1 (phr) & A2 (phr) & A3 (phr) & A4 (phr) \\
\hline NR & 70 & 70 & 70 & 70 \\
BR & 30 & 30 & 30 & 30 \\
ZnO & 5 & 5 & 5 & 5 \\
Stearic acid & 2 & 2 & 2 & 2 \\
HAF & 50 & 50 & 50 & 50 \\
Aromatic oil & 7.0 & 7.0 & 7.0 & 7.0 \\
Vulcanox HS & 0.5 & 0.5 & 0.5 & 0.5 \\
40-20 & 0.5 & 0.5 & 0.5 & 0.5 \\
ZDC & 0.75 & 1.0 & 1.25 & 1.50 \\
Zn(bxt) & 1.0 & 1.0 & 1.0 & 1.0 \\
Sulfur & 2.2 & 2.2 & 2.2 & 2.2 \\
\hline
\end{tabular}

result in the over vulcanization of the rubber compound and shrinking of the nylon cord inside the tire. So, repairing at a lower temperature can prevent deterioration in the quality and lifetime of the repaired product. The low temperature curing property of xanthate/ZDC accelerator combination is investigated through this work.

This paper reports the vulcanization of NR, BR, and NR/BR blend using $\mathrm{Zn}(\mathrm{bxt})_{2} / \mathrm{ZDC}$ accelerator combination at various temperatures, and the effect of temperature of curing on the mechanical properties of the vulcanizates.

\section{EXPERIMENTAL}

\section{Materials used}

NR (ISNR-5, Mooney Viscosity ML $(1+4) 100^{\circ} \mathrm{C}$ value of 82 ), was supplied by the Rubber Research Institute of India, Kottayam. BR ( $97 \%$ 1,4(cis); Mooney viscosity $\mathrm{ML}(1+4)$ at $\left.100^{\circ} \mathrm{C}, 48.0\right)$. Compounding ingredients, such as zinc oxide, stearic acid, ZDC, carbon black (HAF N 330), aromatic oil, vulcanox 40-20, HS, and sulfur, were of commercial grade. $n$-Butyl alcohol, potassium hydroxide, carbon disulphide and toluene used for swelling studies were of reagent grade. Zinc sulfate used for precipitation was of commercial grade.

TABLE II

Formulation of Mixes

\begin{tabular}{lcccc}
\hline \multicolumn{1}{c}{ Mix } & B1 (phr) & B2 (phr) & B3 (phr) & B4 (phr) \\
\hline NR & 70 & 70 & 70 & 70 \\
BR & 30 & 30 & 30 & 30 \\
ZnO & 5 & 5 & 5 & 5 \\
Stearic acid & 2 & 2 & 2 & 2 \\
HAF & 50 & 50 & 50 & 50 \\
Aromatic oil & 7.0 & 7.0 & 7.0 & 7.0 \\
Vulcanox HS & 0.5 & 0.5 & 0.5 & 0.5 \\
40-20 & 0.5 & 0.5 & 0.5 & 0.5 \\
ZDC & 1.0 & 1.0 & 1.0 & 1.0 \\
Zn(bxt) & 0.75 & 1.0 & 1.25 & 1.5 \\
Sulfur & 2.2 & 2.2 & 2.2 & 2.2 \\
\hline
\end{tabular}

TABLE III

Cure Characteristics of the Mixes Given in Tables 1 and 2

\begin{tabular}{lccccc}
\hline $\begin{array}{l}\text { Mix } \\
\text { no. }\end{array}$ & $\begin{array}{c}\text { Min. } \\
\text { torque } \\
(\mathrm{N} / \mathrm{m})\end{array}$ & $\begin{array}{c}\text { Max. } \\
\text { torque } \\
(\mathrm{N} / \mathrm{m})\end{array}$ & $\begin{array}{c}\text { Scorch } \\
\text { time } \\
(\mathrm{min})\end{array}$ & $\begin{array}{c}\text { Optimum } \\
\text { cure time } \\
(\mathrm{min})\end{array}$ & $\begin{array}{c}\text { Cure } \\
\text { rate }\end{array}$ \\
\hline A1 & 0.04102 & 0.4213 & 0.752 & 2.08 & 0.5102 \\
A2 & 0.04541 & 0.4883 & 0.662 & 1.86 & 0.5678 \\
A3 & 0.04248 & 0.4150 & 0.620 & 1.99 & 0.4952 \\
A4 & 0.04395 & 0.4512 & 0.560 & 2.10 & 0.4930 \\
B1 & 0.03965 & 0.3896 & 0.671 & 2.14 & 0.3896 \\
B2 & 0.04539 & 0.4882 & 0.662 & 1.86 & 0.5679 \\
B3 & 0.04651 & 0.4816 & 0.516 & 1.87 & 0.5658 \\
B4 & 0.04662 & 0.4796 & 0.462 & 1.93 & 0.5236 \\
\hline
\end{tabular}

$\mathrm{Zn}(\mathrm{bxt})_{2}$ was prepared in the laboratory as per the procedure reported earlier. ${ }^{20}$ Black filled NR, BR, and NR/BR blend compounds were prepared on a mixing mill.

To optimize the amount of accelerator for vulcanization, the concentration of ZDC was changed from 0.75 to $1.5 \mathrm{phr}$ as shown in Table I, and the concentration of $\mathrm{Zn}(\mathrm{bxt})_{2}$ was changed from 0.75 to $1.5 \mathrm{phr}$ as shown in Table II. The cure characteristics of the mixes were determined using a Goettfert elastograph model 67.85 as per ASTM.D.1646(1981) at $150^{\circ} \mathrm{C}$. The minimum torque, maximum torque, scorch time, optimum cure time, and the cure rate of the above mixes, were reported in Table III.

$\mathrm{NR}, \mathrm{BR}$, and NR/BR blend were compounded on a $\left(6 \times 12^{\prime \prime}\right)$ laboratory mixing mill according to the formulations given in Table IV. As compared with NR, BR requires less sulfur and more accelerators. ${ }^{21}$ So, when the amount of BR in the blend is changed, the concentration of accelerators and the concentration of sulfur are slightly changed as shown in Table IV. The cure curves of the mixes A, B, and D (given in Table IV) at $150^{\circ} \mathrm{C}$ are shown in Figure 1. The optimum cure times of the compounds $\mathrm{A}$ to $\mathrm{E}$ (given in Table IV) were determined at various temperatures from 60 to $150^{\circ} \mathrm{C}$ and are reported in Table $\mathrm{V}$. These compounds were molded in an electrically heated laboratory hydraulic press at various temper-

TABLE IV

Formulation of Mixes

\begin{tabular}{lccccc}
\hline \multicolumn{1}{c}{ Mix } & A (phr) & B (phr) & C (phr) & D (phr) & E (phr) \\
\hline NR & 100 & - & 80 & 70 & 60 \\
BR & - & 100 & 20 & 30 & 40 \\
ZnO & 5 & 5 & 5 & 5 & 5 \\
Stearic acid & 2 & 2 & 2 & 2 & 2 \\
HAF & 50 & 50 & 50 & 50 & 50 \\
Aromatic oil & 7.0 & 7.0 & 7.0 & 7.0 & 7.0 \\
Vulcanox HS & 0.5 & 0.5 & 0.5 & 0.5 & 0.5 \\
40-20 & 0.5 & 0.5 & 0.5 & 0.5 & 0.5 \\
ZDC & 0.75 & 1.0 & 0.9 & 1.0 & 1.1 \\
Zn(bxt) & 1.0 & 1.5 & 0.9 & 1.0 & 1.1 \\
Sulfur & 2.5 & 2.0 & 2.3 & 2.2 & 2.1 \\
\hline
\end{tabular}

Journal of Applied Polymer Science DOI 10.1002/app 


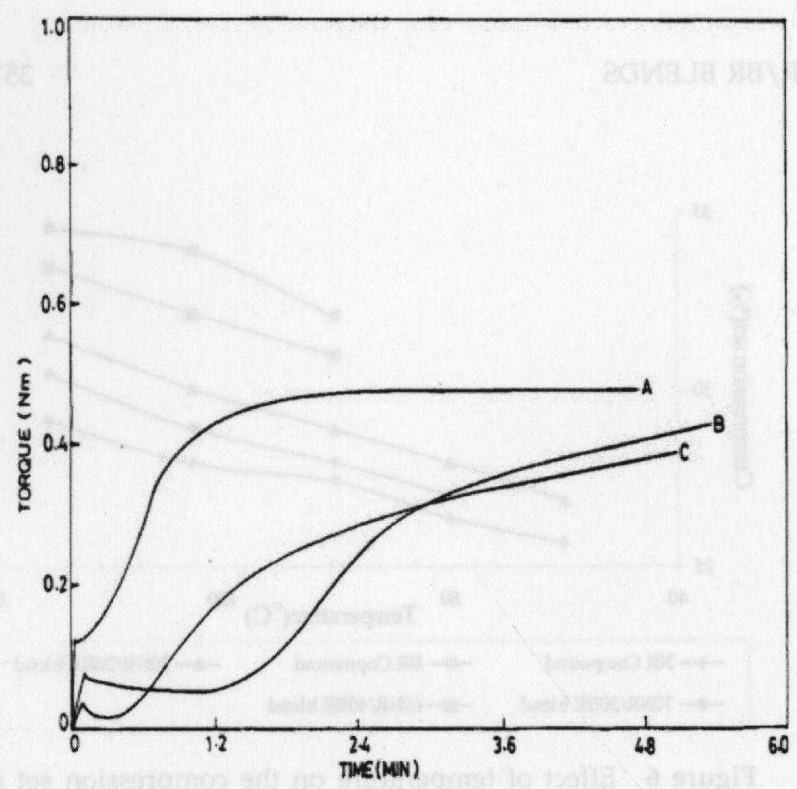

Figure 1 Cure curves of the mixes A, B, and D given in Table IV.

atures upto their optimum cure times at a pressure of $200 \mathrm{~kg} / \mathrm{cm}^{2}$. Dumb bell shaped tensile test pieces were punched out of these compression molded sheets along the mill grain direction. Crosslink density of the samples was determined by equilibrium swelling method using toluene as the solvent. The degree of crosslinking was calculated using the Florey Rehner equation ${ }^{22}$ and is shown in Figure 2. The tensile properties of the vulcanizates were evaluated on a Zwick universal testing machine using a cross- head speed $500 \mathrm{~mm} / \mathrm{min}$ according to ASTM.D.2240 and are graphically represented in Figures 3-5. Compression set was determined by compressing to a constant deflection (25\%) as per ASTM. D. 395-61, method B (Fig. 6). Abrasion resistance was tested using DIN abrader according to DIN 53,516 (Fig. 7).

\section{RESULTS AND DISCUSSION}

Table III gives the cure characteristics of the mixes given in Tables $I$ and II. It shows that compound $B_{2}$ and $B_{3}$ have the same optimum cure times. But the

TABLE V

Optimum Cure Times in Minutes

\begin{tabular}{crrrrr}
\hline Temp. $\left({ }^{\circ} \mathrm{C}\right)$ & A & B & C & D & E \\
\hline 150 & 1.26 & 4.0 & 1.41 & 1.86 & 3.86 \\
125 & 6.11 & 13.0 & 6.36 & 7.1 & 11.96 \\
100 & 21.24 & 41.0 & 22.02 & 23.16 & 38.64 \\
80 & 53.62 & - & 55.42 & 56.98 & - \\
60 & 78.31 & - & 80.16 & - & - \\
\hline
\end{tabular}

Journal of Applied Polymer Science DOI 10.1002/app

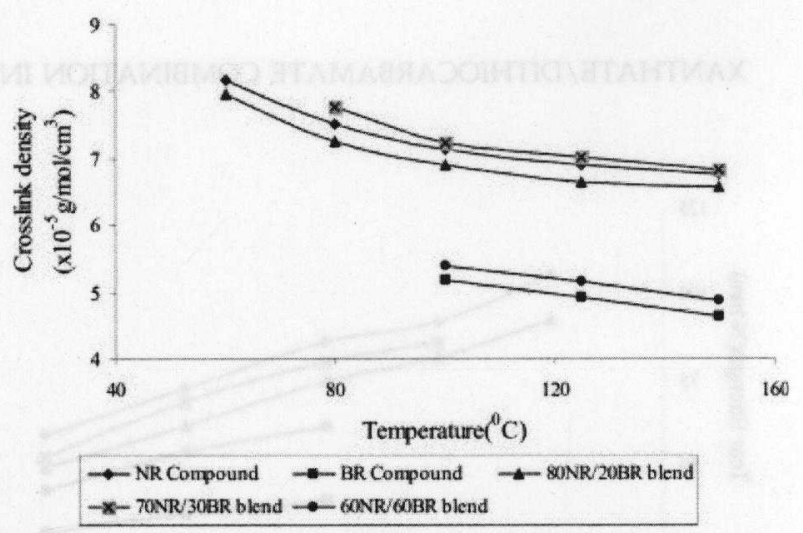

Figure 2 Effect of temperature on the crosslink density of the compounds given in Table IV.

maximum torque and cure rate are high for the compound $\mathrm{B}_{2}$. This compound is having enough scorch safety also. So $1.0 \mathrm{phr} \mathrm{ZDC}$ and $1.0 \mathrm{phr} \mathrm{Zn}(\mathrm{bxt})_{2}$ are taken as the optimum dosage for the $70 / 30 \mathrm{NR} / \mathrm{BR}$ blend.

Figure 1 shows the cure curves of the mixes A, B, and $\mathrm{D}$ at $150^{\circ} \mathrm{C}$. It is seen that the $100 \%$ NR based compound (compound A), cures faster than all the other compounds and the scorch time is found to be very low. But in $100 \%$ BR based compound (compound B), the curing is very slow as expected. Since the double bond in NR is more active because of the presence of $-\mathrm{CH}_{3}$ group, the curatives will be slightly more soluble in NR, which leads to a high cure rate for NR (compared to BR). The blend compound (compound D) gives enough scorch safety and at the same time, the cure time is very close to that of NR. This shows that blending of BR with NR improves scorch safety without much change in the cure time.

Table $\mathrm{V}$ shows the optimum cure times of the compounds given in Table IV at different tempera-

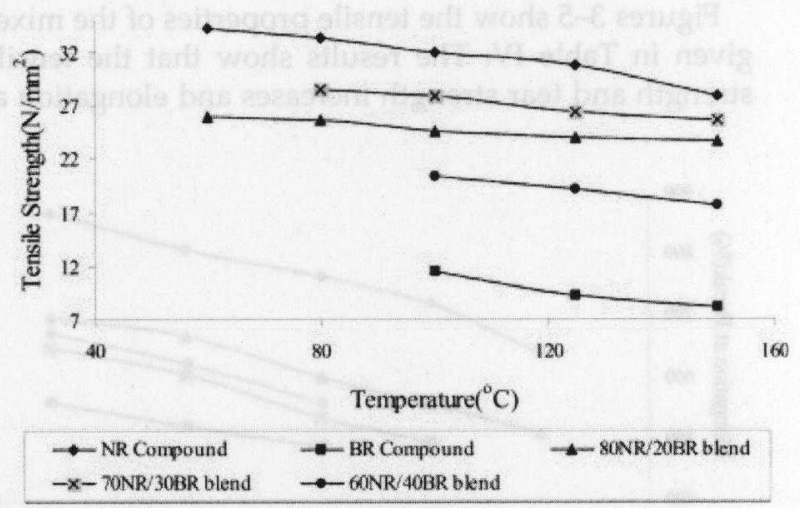

Figure 3 Effect of temperature on the tensile strength of the compounds given in Table IV. 


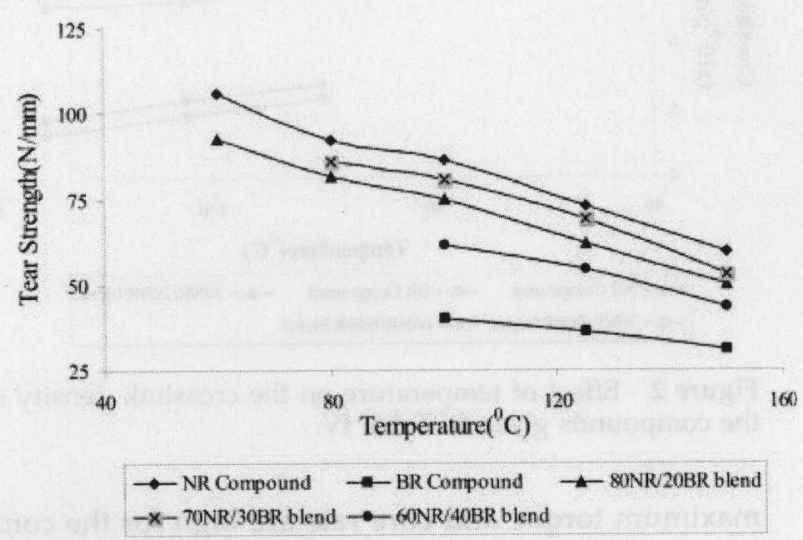

Figure 4 Effect of temperature on the tear strength of the compounds given in Table IV.

tures. Compound A undergoes curing at all temperatures from 150 to $60^{\circ} \mathrm{C}$ with gradual increase in cure time. Compound B doesn't cure below $100^{\circ} \mathrm{C}$. Compound $\mathrm{C}$ undergoes curing up to $60^{\circ} \mathrm{C}$ and the cure times are closer to that of pure NR compounds. With compound D, curing takes place only up to $80^{\circ} \mathrm{C}$. At $60^{\circ} \mathrm{C}$, curing is incomplete even after $2 \mathrm{~h}$. Compound E doesn't cure below $100^{\circ} \mathrm{C}$. So it is clear that low temperature curing becomes difficult as the amount of BR in the blend increases and it is impossible with $100 \%$ BR compounds.

Figure 2 shows the total crosslink density of the compounds A to E. Compared to NR vulcanizates, crosslink density of BR vulcanizates is very low. Among the blends, 80/20 NR/BR blend shows a crosslink density comparable to pure NR vulcanizates. Crosslink density of $70 / 30$ blend is slightly higher than that of NR vulcanizates. $60 / 40$ blend shows low crosslink density, closer to that of pure BR vulcanizates.

Figures 3-5 show the tensile properties of the mixes given in Table IV. The results show that the tensile strength and tear strength increases and elongation at

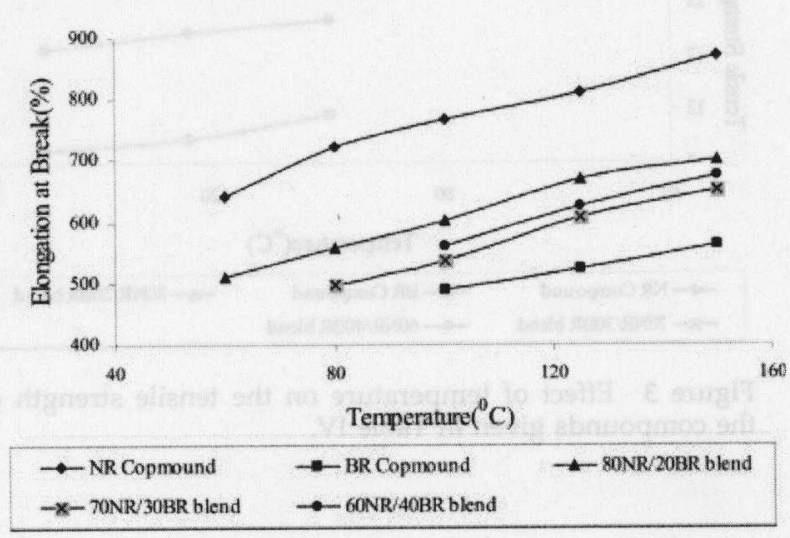

Figure 5 Effect of temperature on the elongation at break of the compounds given in Table IV.

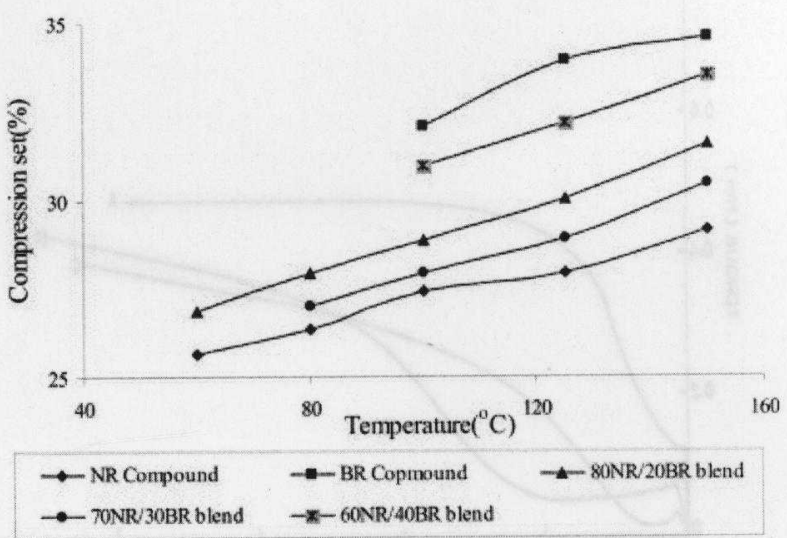

Figure 6 Effect of temperature on the compression set of the compounds given in Table IV.

break decreases when the temperature of curing is changed from 150 to $60^{\circ} \mathrm{C}$. This may be due to lesser degradation of the rubber at lower temperatures and also due to the higher stability of the accelerator at lower temperatures. At a particular temperature, the tensile properties are maximum for NR compounds, minimum for BR compounds and in between for the blends. But the tensile properties of the blends are closer to the NR compounds than that of BR compounds. The elongation at break is also close to the arithmetic average. Among the three blends, the tensile properties are maximum for the $70 / 30$ blend.

Figure 6 shows the compression set of the mixes $\mathrm{A}$ to $\mathrm{E}$ at different temperatures. Compression set values of the BR compounds is high compared to that of NR compounds. The values for the blends are intermediate between that of NR and BR.

Figure 7 shows the abrasion resistance of the vulcanizates given in Table IV. The abrasion resistance is high for the BR compounds at high temperatures than that of NR compounds. The abrasion resistance values of the $70 / 30$ and $60 / 40$ blends are closer to

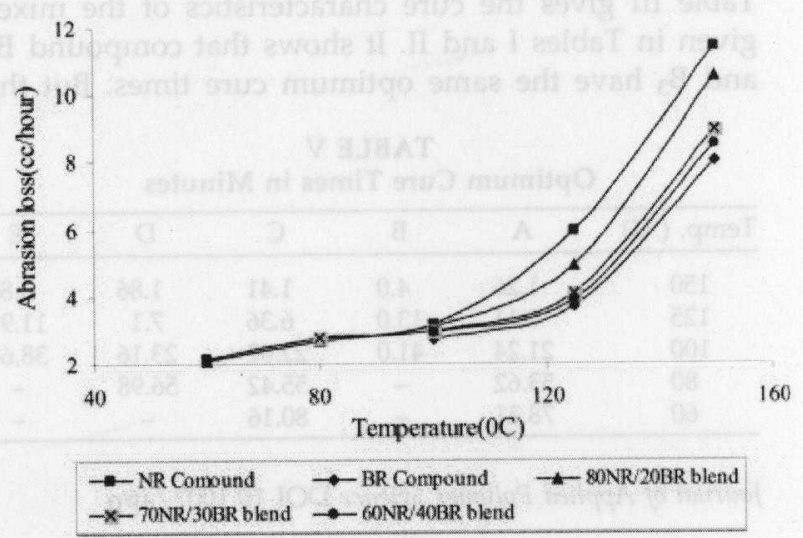

Figure 7 Effect of temperature on the abrasion resistance of the compounds given in Table IV. 
that of the $100 \%$ BR based compounds at or below $100^{\circ} \mathrm{C}$. The $80 / 20$ blend shows abrasion resistance value closer to that of the NR compounds. Below $100^{\circ} \mathrm{C}$, the abrasion resistance values of all the blends are closer to that of NR vulcanizates and a high value is shown by the $70 / 30$ blend. So, addition of $\mathrm{BR}$ to NR improves the abrasion resistance, at high temperatures.

The $80 \mathrm{NR} / 20 \mathrm{BR}$ blend shows more or less the properties of NR alone because of the low concentration of BR. When the amount of BR in the blend increases to $30 \mathrm{phr}$, the properties settle at an intermediate value between those of BR and NR. This may be due to the good compatibility of the two rubbers resulting in an almost single phase behavior. $^{23,24}$ When the amount of BR in the blend is $40 \mathrm{phr}$, the properties are closer to BR

\section{CONCLUSIONS}

1. $\mathrm{Zn}(\mathrm{bxt})_{2} / \mathrm{ZDC}$ accelerator combination can vulcanize NR at all temperatures from 150 to $60^{\circ} \mathrm{C}$; but it can vulcanize $\mathrm{BR}$ only upto $100^{\circ} \mathrm{C}$. Among the NR/BR blends, $80 / 20$ blend undergoes curing at all temperatures from 150 to $60^{\circ} \mathrm{C}, 70 / 30$ blend cures only upto $80^{\circ} \mathrm{C}$, and $60 / 40$ blend cures only upto $100^{\circ} \mathrm{C}$.

2. Addition of BR to NR increases the scorch time of the compound.

3. The tensile properties of the pure BR compounds are poor compared to the NR compounds.

4. The mechanical properties of the $80 \mathrm{NR} / 20 \mathrm{BR}$ blends are more closer to that of NR vulcanizates, that of $60 / 40$ blends are more closer to the BR vulcanizates, while the $70 / 30$ blends shows an intermediate property.
5. The $70 / 30 \mathrm{NR} / \mathrm{BR}$ blend and $60 / 40 \mathrm{NR} / \mathrm{BR}$ blend show better abrasion resistance than the NR vulcanizates when cured at higher temperatures.

\section{References}

1. Walters, M. H.; Keyte, O. N. Rubber Chem Technol 1965, 38, 62.

2. Railsback, H. E.; Cooper, W. T.; Stumpe, N. A. Rubber Chem Technol 1959, 32, 308.

3. Paul, D.R.; Newman, S. Polymer Blends, Vols. 1 \& 2; Academic Press: New York, 1978.

4. Bruins, P.F., Ed. Polyblend and Composites; Appl Polym Symp 15, 1970

5. Bhowmick, T. K.; Bhattacharya, A. K.; Gupta, B. R.; Anil, K. B. Plast Rubber Compos Process Appl 1988, 10, 105.

6. Corish, P. J. Rubber Chem Technol 1967, 40, 324.

7. Utracki, L. A. Polym Plast Technol Eng 1984, 22, 27.

8. Sarah, Y. K. Plast Eng 1987, 41.

9. Xanthos, M.; Dagli, S. S. Polym Eng Sci 1991, 31, 929.

10. Manson, J. A.; Sperling, L. M. Polymer Blends and Composites; Plenum: New York, 1976.

11. Kovar, J.; Fortelny, J.; Bodhanecky, M. Int Polym Sci Technol $1982,9, \mathrm{~T} / 50$.

12. Martuscelli, E; Palumbo, R.; Kryszewski, M. Polymer Blends, New York, 1980.

13. Walters, M. H.; Keyte, D. N. Rubber Chem Technol 1965, 38, 63.

14. Hess, M. W.; Vegvari, P. C.; Swor, R. A. Rubber Chem Technol $1985,58,350$.

15. Sarbach, D. V. Rubber Age 1961, 89, 283

16. Sarbach, D. V.; Hallman, R.W.; Cavicchia, M. A. Rubber Age $1966,98,67$.

17. Palaty, S.; Joseph, R. Plast Rubber Compos 2001, 30, 6.

18. Sasidharan, K. K.; Gopalakrishnan, K. S.; George, K. E. J Appl Polym Sci 2005, 94, 1164.

19. Shiny, P.; Rani, J. Iranian Polym J 2004, 13, 85.

20. Shiny, P.; Rani, J. J Appl Polym Sci 2000, 78, 1769.

21. Balckley, D. C. Synthetic Rubbers; Applied Sciences Publishers: London, 1983.

22. Flory, P. J.; Rehner, J. J Chem Phys 1943, 11, 512.

23. Inoue, T. Int Polym Sci Technol 1981, 8, T65.

24. Baranwal, K. C.; Son, P. N. Rubber Chem Technol 1974, 47, 88. 